\title{
Failure Analysis of a Jet Engine High Pressure Turbine Blade
}

\author{
David Christie $^{1}$ \\ ${ }^{1}$ Senior Failure Analysit, IMR Test Labs, Lansing NY, USA
}

Jet aircraft engines periodically are removed from service for overhaul. Operations include the refurbishment of the high pressure turbine blades, as well as other blades, vanes, and internal engine components. Typically a sample of the blades are sacrificed for metallographic testing to determine if operation has resulted in microstructural changes due to high temperature operation. Creep voids, over-aging, agglomeration of carbides, and formation of deleterious phases are assessed. The various coatings that enable high temperature operation are chemically stripped from the blades, followed by grinding, re-welding the Z-form hardface deposits, and re-coating. The parts undergo numerous non-destructive examinations throughout the process to assure that they will endure another service cycle. Finally, the engine is re-assembled and tested on a stand before being re-installed on an aircraft. A failure of any engine component at this point is viewed as a serious matter. Three high pressure cast nickel superalloy (Rene' 77 ) turbine blades were received by IMR Test Labs, one of which had fractured through the airfoil during an outgoing engine test. The task was to determine the root cause of fracture of the blade.

Visual examination of the fracture surface revealed an interesting, three zone fracture morphology. Modern aircraft engine high pressure turbine blades are complex castings, with internal passages and webs to support the airfoil section. The internal passages serve two purposes - they lighten the blades, turning the airfoils into structural "wings", and they allow the passage of cooling gases to keep the blade material substantially cooler than the external combustion gases flowing over the airfoil surface. In the fractured blade, a region encompassing the fractured internal webs was covered with a high temperature oxide scale. From this darkened surface a second fracture zone extended that exhibited radiating ridges and fan-shaped patterns. Near the leading and trailing edges of the airfoil section a third fracture morphology was present, which was a rougher surface with no radiating pattern.

Under low power stereo optical microscope and scanning electron microscope (SEM) examination the story behind the failure was revealed. The oxidized fracture zone clearly had formed or been exposed to engine operating temperatures for a protracted time. This could only have happened during previous service, not during the short engine outgoing test. From this pre-existing crack high cycle fatigue (HCF) initiated at multiple locations. It is not clear when these fatigue cracks started, but the presence of a light high temperature oxide layer over most of the fatigue crack zone suggests that they had grown significantly during previous service cycles. It is likely that only a small percentage of additional fatigue growth occurred during the engine test. The third fracture zone was rapid ductile overload fracture that resulted in liberation of the airfoil section of the part.

Examination of the microstructure of the fractured and non-fractured blades revealed additional oxidation cracks in the webs. These cracks followed grain boundaries in this relatively large grained material. Large grains size imparts greater creep resistance in nickel superalloys in high temperature service. However, the grain boundaries exhibit increased susceptibility to oxidation and growth of carbides. The prevention of oxidation cracks depends on the formation of a tight, oxygen resistant scale 
on the internal web surfaces. The root cause of the fracture of this blade can be assigned to the failure of the internal oxide scale layer to prevent selective oxidation of the grain boundaries. Later revisions of this part number incorporated an aluminide vapor deposition coating on the internal cavities to increase resistance to oxidation. A surprisingly similar HPT blade fracture occurred in an engine on test in Australia in 2006 [1].

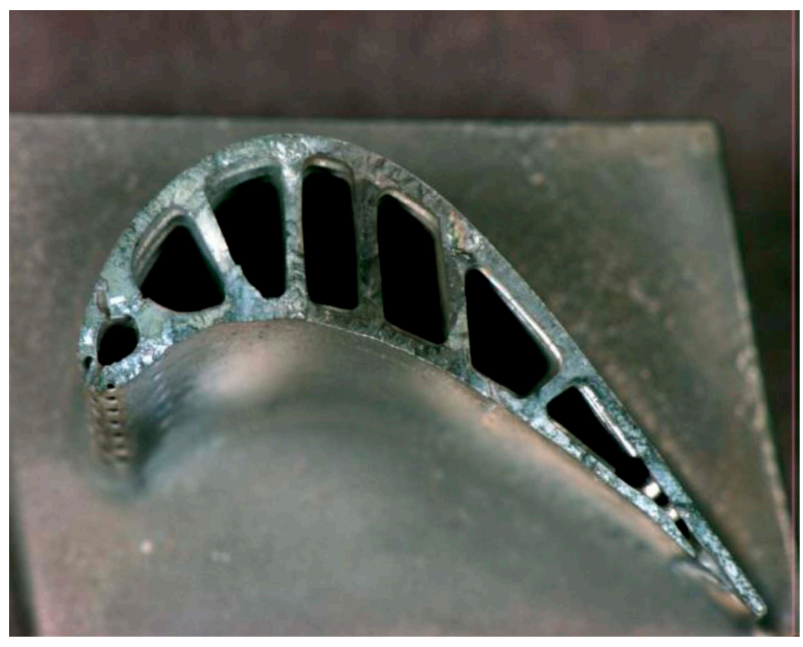

Figure 1. The fracture surface of the failed HPT blade. The dark region over the $4^{\text {th }}$ and $5^{\text {th }}$ web from the leading edge is oxidation cracking.

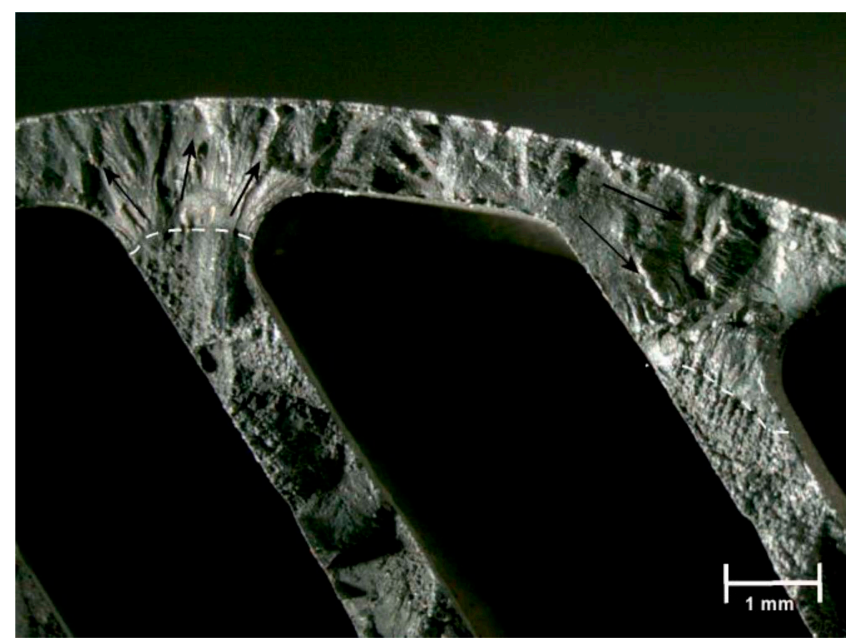

Figure 2. The fracture surface at higher magnification. The black arrows show the direction of fatigue crack growth. The white dashed lines show the limits of the oxidation cracks.

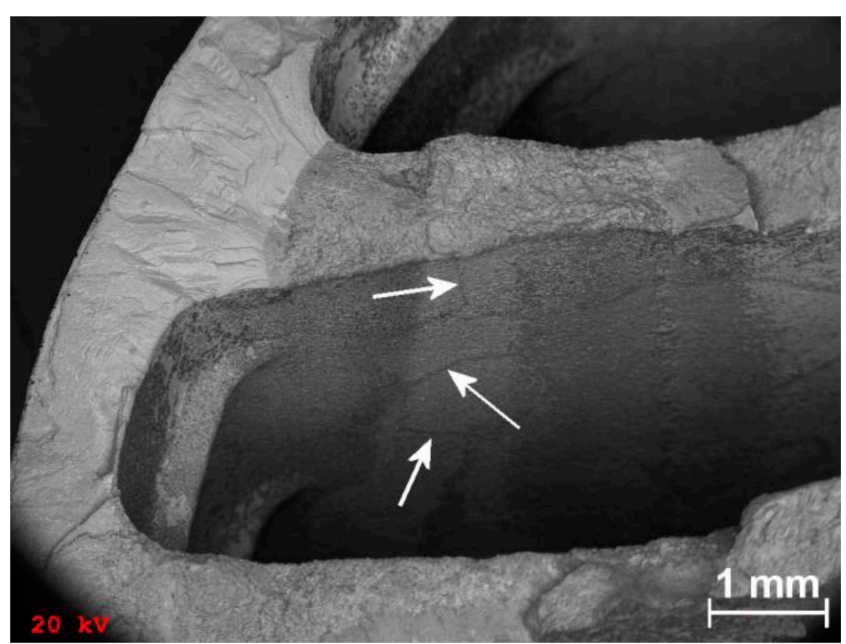

Figure 3. Additional oxidation cracks were noted in the webs (white arrows).

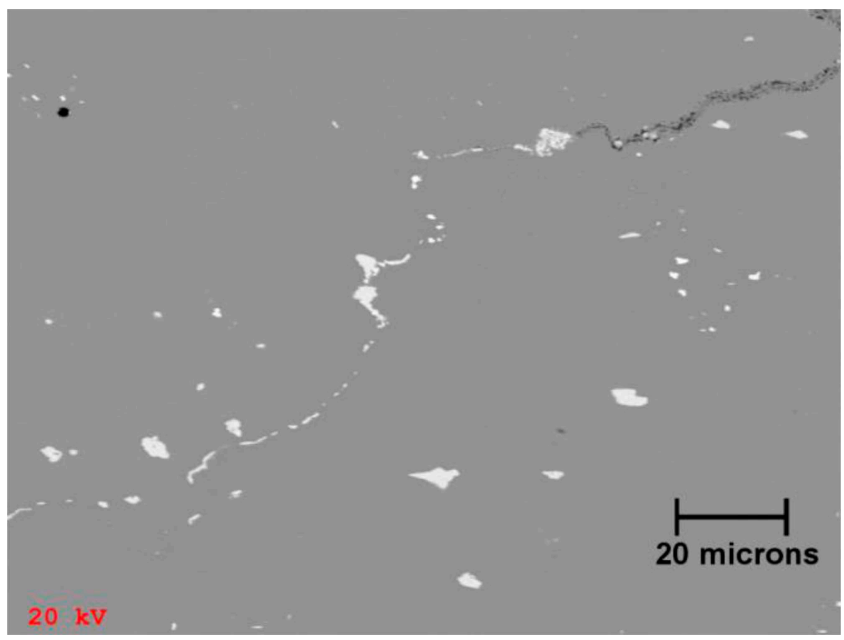

Figure 4. SEM backscatter image of grain boundary carbides and the tip of the oxidation crack.

\section{References:}

[1] ATSB TRANSPORT SAFETY INVESTIGATION REPORT Technical Analysis 23/2006 